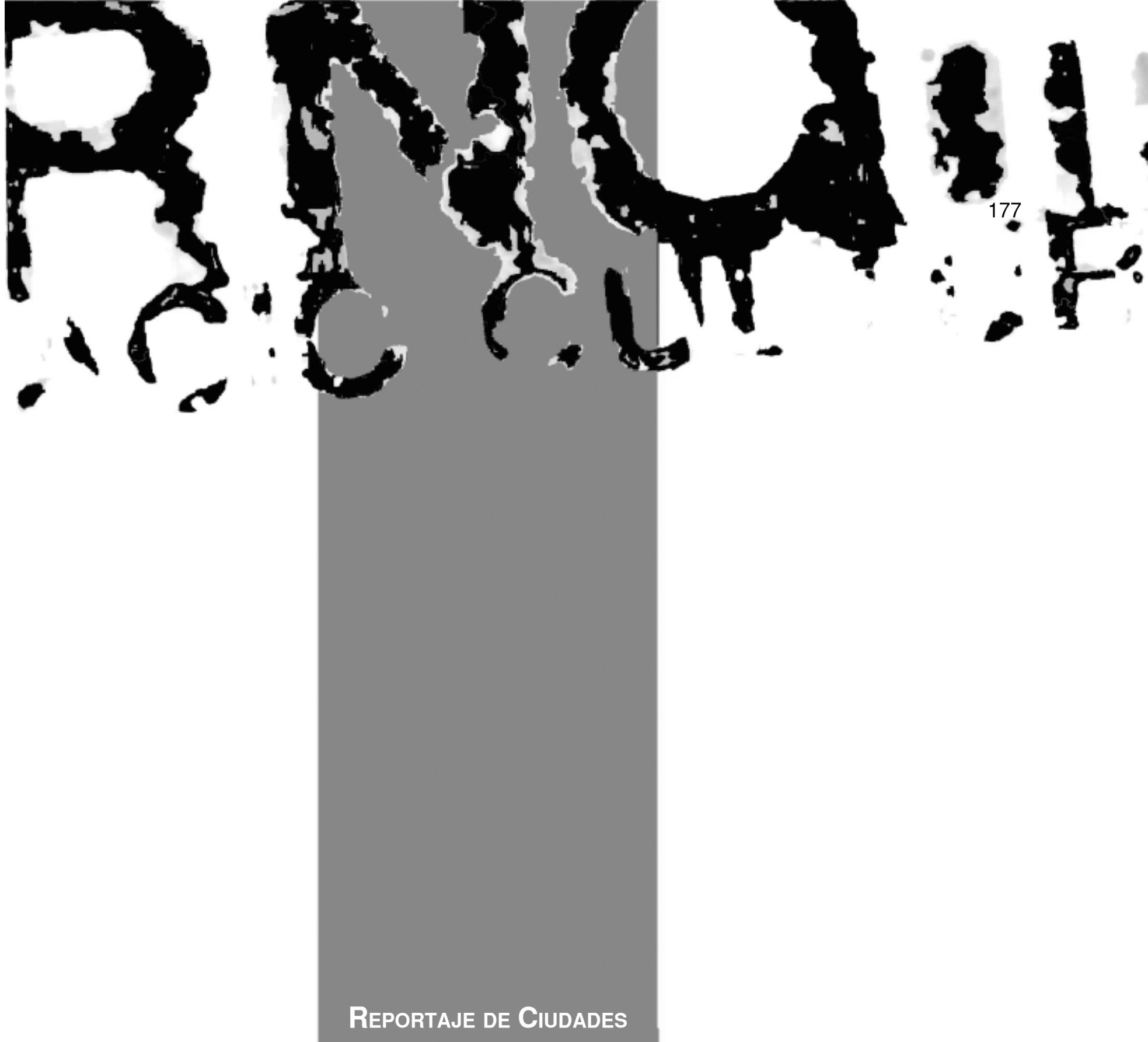

Cuaderno Urbano N5,pp. 177-184, Resistencia, Argentina, Junio 2006 
178 


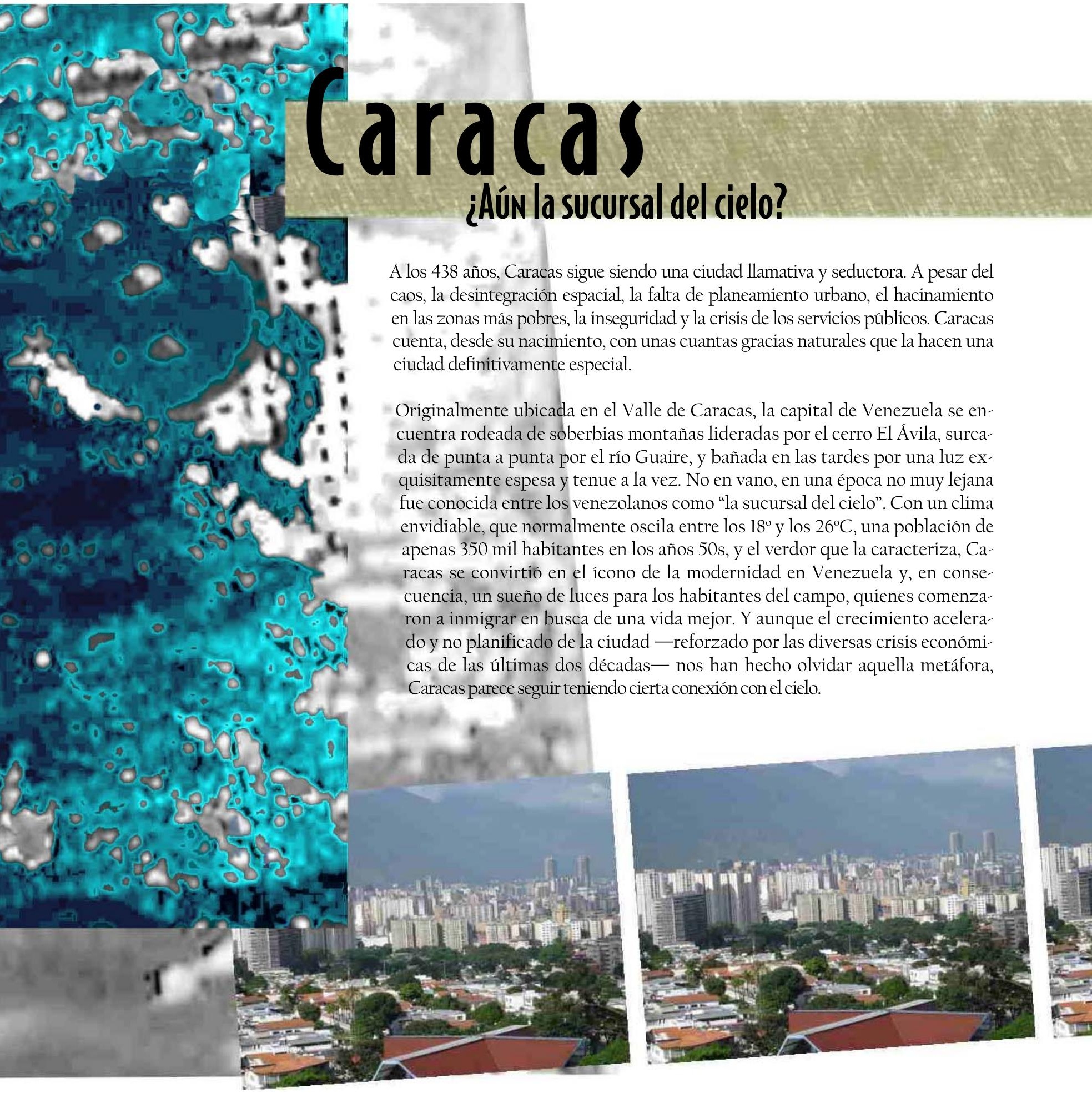




\section{aracas ¿Aún la sucursal del cielo?}

Como observara Alan Gilbert (1998: 9) en su libro The Latin American City, en Caracas "todo parece estar en el aire: montañas, edificios de apartamentos, bloques de oficinas, avisos publicitarios, y hasta las barriadas". Ciertamente, aparte de su forma alargada, siguiendo el curso del río Guaire y los vaivenes del Ávila en 25 kilómetros de Este a Oeste - mientras cuenta con apenas unos cinco kilómetros de ancho-, Caracas es una ciudad definitivamente vertical, donde un tridimensional imaginario urbano, con seguridad, cuenta con la altura como un elemento clave, producto tanto de la naturaleza como de la arquitectura caraqueñas.

Caracas es una ciudad que siempre puede ser vista desde arriba y hacia arriba. Por estar contenida en un espacio geográfico limitado por montañas de diferentes alturas, y al mismo tiempo tener rascacielos y altos edificios residenciales y comerciales, desde prácticamente cualquier sitio de la ciudad se puede ver buena parte de ella. No es necesario subir al magnífico Hotel Humboldt, situado en la cima del Avila, a 2.200 metros de altura sobre el nivel del mar, para apreciar buena parte de la extensión caraqueña, y contemplar la amalgama de espacios tomados por asalto por la modernidad, la pobreza, el consumismo, el nuevorriquismo o la exclusión.

Visible desde toda la ciudad, el cerro El Ávila es el Norte del caraqueño. Es la única referencia que no cambia en Caracas, una ciudad caracterizada por un vertiginoso cambio morfológico y referencial. El Ávila, majestuoso, es el único cerro intocable de la ciudad. Su condición de Parque Nacional le ha otorgado inmunidad frente a las invasiones y a
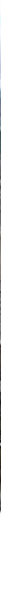


\section{aracas ¿Aún la sucursal del cielo?}

Cualquier análisis contemporáneo de Caracas debe enmarcarse en la idea de región, noción que ha venido a sustituir la vieja concepción de cuidad —con sólo un centro y varias ciudades satélite - por una visión más funcional y dinámica de las relaciones socio-espaciales que conforman lo que hoy vemos, sentimos y vivimos como ciudad: la Gran Caracas. La ciudad ha crecido fundamentalmente hacia el sur y ahora se habla del Gran Valle. La conforman cinco municipios: Libertador, Chacao, Baruta, Sucre y El Hatillo, que en su conjunto y como unidad político territorial constituyen el Distrito Metropolitano de Caracas. Sin embargo, al menos 12 jurisdicciones distintas forman parte de la dinámica metropolitana.

El funcionamiento de esta entidad supramunicipal, sin embargo, es tan confuso y caótico como la dinámica urbana de Caracas, y está muy marcado por las diferencias políticas que existen entre los alcaldes. Estas diferencias, aunadas a una seria crisis de gobernabilidad, se han reflejado también en la apropiación de los espacios públicos por parte de los ciudadanos. Entre las viviendas privadas y las propiedades comerciales existen los espacios públicos que conectan y articulan la ciudad — ciudad en términos de espacio y de gente- y que parecieran moldearse y transformarse a sí mismos, paralelamente al surgimiento de nuevos patrones de espacios privados. Es evidente que la depresión económica y el crimen han cambiado dramáticamente los espacios y la vida pública y privada. Los crecientes niveles de desigualdad social y las tensiones políticas de los últimos años en Venezuela han producido nuevas formas de manipular la exclusión en la ciudad. La privatización - mayormente ilegal- de los espacios públicos puede ser vista como una demanda o reclamo de los ciudadanos que han sido abandonados por la democracia. Esto genera una incapacidad de compartir los espacios públicos, resultado de las fallas de la democracia en asegurar efectivamente el ejercicio de los derechos civiles, políticos y socioeconómicos de los ciudadanos. Y la demanda por el uso de los espacios públicos de maneras diferentes podría percibirse como una inesperada expresión o ejercicio de ciudadanía.

El centro histórico de Caracas es ahora sede de miles de vendedores informales, mejor conocidos como "buhoneros", y también símbolo de los afectos al partido de gobierno quienes han tomado permanentemente una de las esquinas de la Plaza Bolívar, llamada "la esquina caliente", en un intento, tal vez, por tomar el control en situaciones de conflicto en los espacios públicos. Respecto de la propiedad privada, la fortificación de viviendas y calles (con barras en puertas y ventanas, murallas, casetas de vigilancia, barras de acceso, seguridad privada) es ahora la práctica común, cambiando así la arquitectura y el flujo de relaciones e 


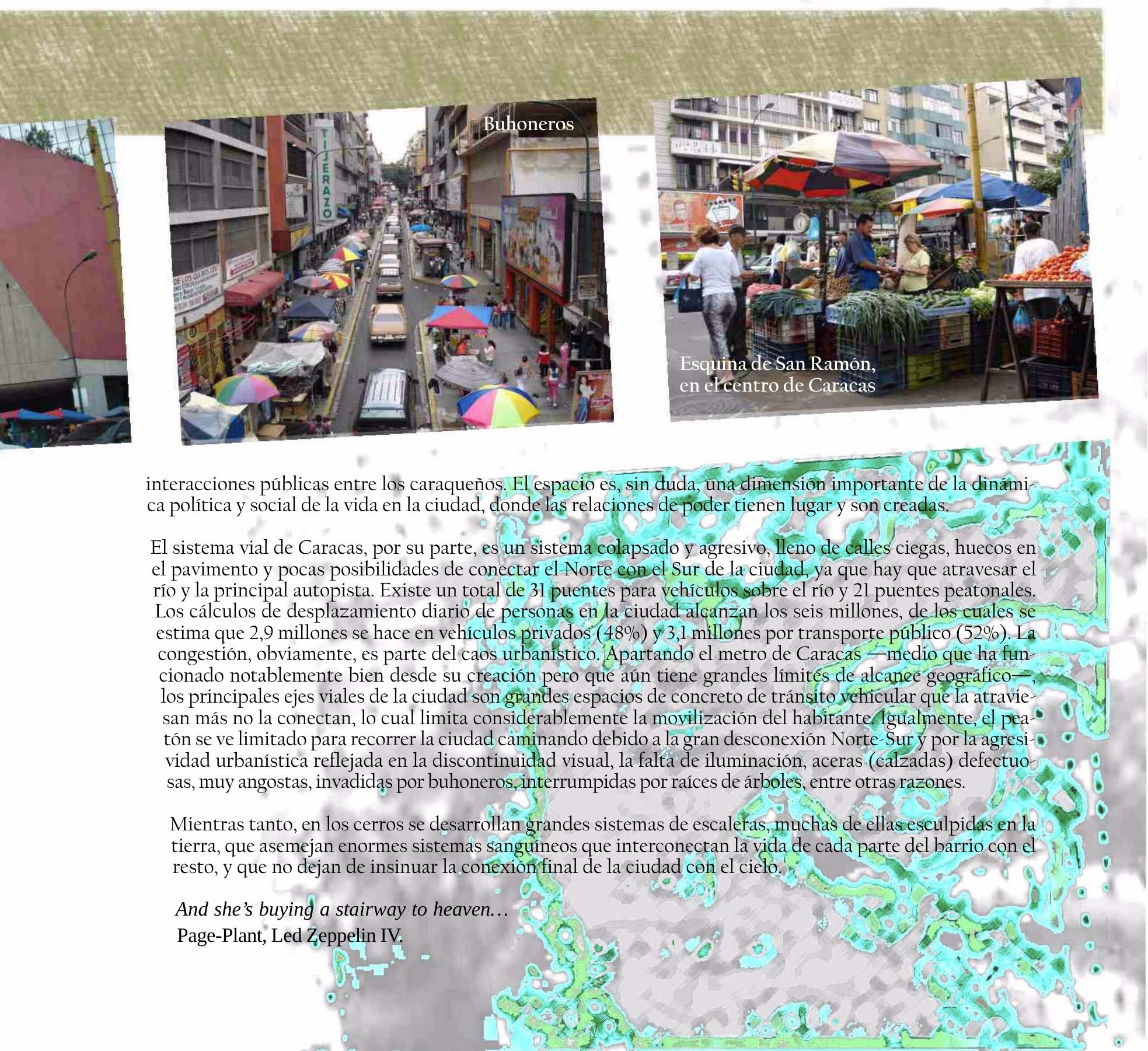

